\title{
Wind Energy Potential in Gaza Strip-Palestine state
}

\author{
Yasser Fathi Nassar ${ }^{1}$, Samer Yassin Alsadi \\ ${ }^{1}$ Mechanical Engineering Department, Engineering and Technology Faculty, Sebha University, Brack, \\ Libya \\ ${ }^{2}$ Electrical Engineering Department, Faculty of Engineering and Technology, Palestine Technical \\ University-Kadoorie, Tulkarm, Palestine
}

e-mail: 1yasser_nassar68@ymail.com*,2samer_sadi@yahoo.com

\begin{abstract}
In this study, wind speed and direction data provided by Meteoblue AG-Switzerland as hourly time-series for 16 years from 2000 to 2015 for selected three cities in Gaza Strip, are used directly to evaluate the wind energy in the three selected sites which are geographically presenting the entire Strip. Jabalia is located in the North of Gaza Strip, Deir-albalah in the Middle and Rafah in the South. The wind rose diagrams have been depicted by using WRPLOT view 7.0.0 (wind rose plots for meteorological data from Lake Environmental, 2011). The statistical analysis of the data shows that; Rafah city is the first candidate to establish a wind farm in the entire Palestinian territory. The reason that, Rafah has the highest wind energy potential than the other sites. The second reason is that Rafah is located on the border crossing to Egypt, which facilitates the transfer of machinery, experts, and reduces transport and communication expanses. In addition to low population density, which increases the economic feasibility of utilizing wind energy at this location for remote area applications. The analysis has been done for a large types of wind turbines types. Gamesa G128-4.5 WT, which is manufactured for classes I and II wind speeds with low cut-in speed, was selected for our project. The estimated annual energy is $15,962 \mathrm{MWh} /$ turbine, with an average utility factor of $40.4 \%$; to cover the shortage of $200 \mathrm{MW}$ we need to $110 \mathrm{WTs}$. The required area for the wind farm is estimated to be $43 \mathrm{~km}^{2}$.
\end{abstract}

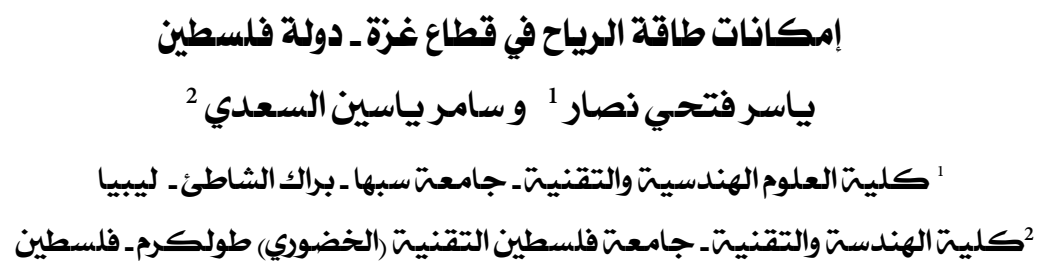

ملخص: أُستخدمت ِِ هذه الدراستة بيانات عن سرعت واتجاه الرياح والتي قدمتها مؤسست Meteoblue للأرصاد والتنبؤات الجويتِ 


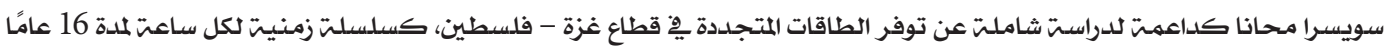

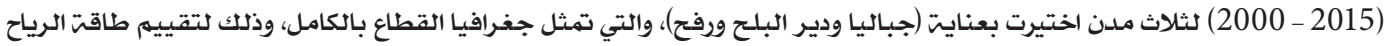

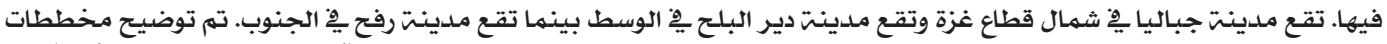

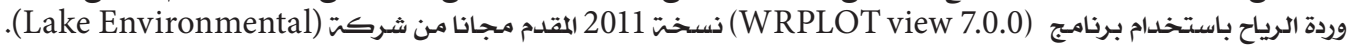

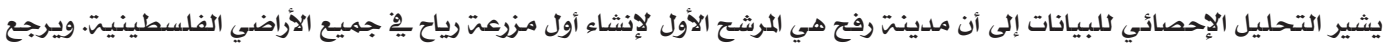

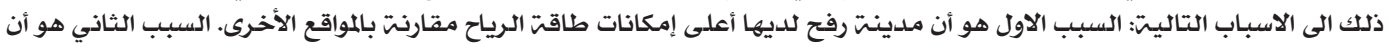

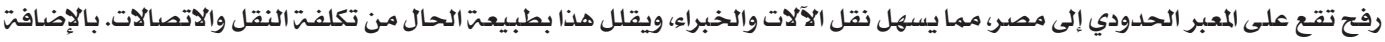

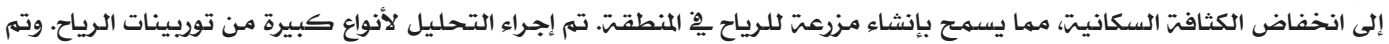

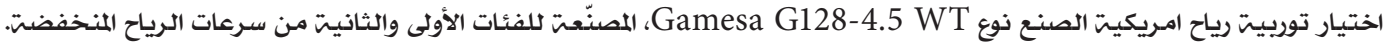

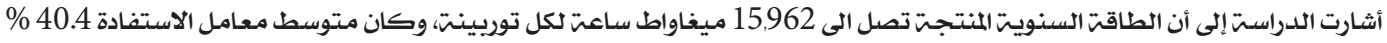

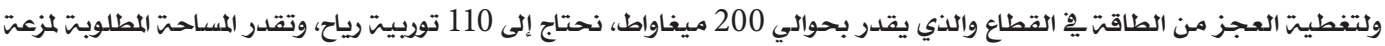

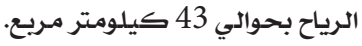

Keywords: Gaza Strip, wind data, wind energy, wind farm, utility factor of wind turbine

\section{NOMENCLATURE}

\begin{tabular}{|c|c|}
\hline A & area swept by the rotor, $\left[\mathrm{m}^{2}\right]$ \\
\hline c & scale parameter \\
\hline cis & cut-in wind speed, $[\mathrm{m} / \mathrm{s}]$ \\
\hline $\cos$ & cut-out wind speed $[\mathrm{m} / \mathrm{s}]$ \\
\hline$f_{w}(v)$ & frequency function \\
\hline$f_{R}(v)$ & Rayleigh distribution \\
\hline$f(v)$ & probability density distribution function \\
\hline $\mathrm{E}_{\text {annual }}$ & annual energy production [Wh/year] \\
\hline $\mathrm{k}$ & shape parameter \\
\hline $\mathrm{P}$ & Pressure, [kPa] \\
\hline$P_{\text {gen }}$ & power generation, $[\mathrm{kW}]$ \\
\hline $\mathrm{P}_{\max }$ & maximum extractable wind power, $[\mathrm{kW}]$ \\
\hline $\bar{P}_{w}$ & average power, $[\mathrm{kW}]$ \\
\hline $\mathrm{v}$ & wind speed, $[\mathrm{m} / \mathrm{s}]$ \\
\hline $\mathrm{T}$ & Temperature, $\left[{ }^{\circ} \mathrm{C}\right]$ \\
\hline$U_{w t}$ & utility factor of the turbine \\
\hline $\mathrm{Z}$ & height, $[\mathrm{m}]$ \\
\hline$\rho$ & air density, $\left[\mathrm{kg} / \mathrm{m}^{3}\right]$ \\
\hline$\sigma$ & variance of the wind speed, $[\mathrm{m} / \mathrm{s}]$ \\
\hline$\Gamma$ & Gamma function \\
\hline
\end{tabular}




\section{INTRODUCTION}

Global population explosion, environmental pollution and rapidly decreasing reserves of oil resources have been matters of social and economic concern that negatively affects human kind life in all aspects for several years. These reasons have encouraged researchers all over the world to look for alternative resources for energy that have less pollution effects, and can cover the shortage of oil resources with lower costs. Wind energy is one of the major alternatives that has been considered and used in several countries in the world. For example, in Denmark 47\% of energy consumption comes from wind power generation stations [1].

Gaza Strip is a small geographical area located along the southeast corner of the Mediterranean. Egypt borders it on the south-west as shown in Figure 1. It is about $41 \mathrm{~km}$ long, the narrowest width is $6 \mathrm{~km}$ and the widest is $12 \mathrm{~km}$ wide, with a total area of $360 \mathrm{~km}^{2}$. It lies on Longitude $34^{\circ} 26$ east and Latitude $31^{\circ} 10$ north of the equator. According to the last census of the Palestinian Central Bureau of Statistics, at the first of April 2018, the population of Gaza Strip is 2.09 million. The average population density is 4,986 people per square kilometres, while in the camps, the density can rise to as high as 100,000 people per square kilometres. The Gaza Strip is categorized as tropical region with a relatively hot summer and mild winter [2].

During the last decade, Gaza Strip suffered from a continuing crisis of electricity supply due to many political issues which have affected the life of the Palestinians. There are three sources for electricity in Gaza: Israelis (120 MW), Egyptian (17 MW) and the Palestine Electric Company (PEC). PEC supply depends mainly on the fuel amount allowed to cross borders that is totally controlled by Israelis and depends on the political situation. The PEC usually provides around $80 \mathrm{MW}$ or more than $50 \%$ of its full capacity of $140 \mathrm{MW}$.

The total electricity supply in the Gaza from all the mentioned sources is about 217 MW. Also, Gaza's electricity demand varies depending on the time of the year. During the summer and winter, Gaza consumes about $440 \mathrm{MW}$, and about $380 \mathrm{MW}$ during the Spring and Fall. Usually, there is a noteworthy shortage of approximately $200 \mathrm{MW}$ through the course of the year; this deficit causes recurring interruption of electrical supply to residential, commercial and public facilities [3].

A recent study showed the wind energy resource mapping of Palestine [4], where the main conclusion was confirmed what Hasan provided early [5], that wind potential all over Gaza is not worth to be utilized. Other studies showed the utilization of wind energy could be feasible in many locations in Palestine for cutting-off electricity production [6-8]. Electricity generation by using wind energy requires studying wind speed based on the available data and topographical features of the land in different locations. The coastal strip region (Gaza Strip) is characterised by a very low wind speed throughout the year, with an annual average of about $2.5-3.5 \mathrm{~m} / \mathrm{s}$.

In fact, the electricity crisis in the Gaza Strip can be solved by exploitation of the local renewable energy resources. The wind energy can have the opportunity to leadership all other energies, so that it does not really need a space dedicated to the farm, as in the solar energy of PV panels, concentrators or heliostats fields, we can use the wind farm land in any other activities. The wind turbines can be deployed along the border with Egypt and the coastal strip along a distance of $22 \mathrm{~km}$. The present study is considered the first comprehensive study of the Gaza Strip, thanks for Meteoblue to provide us with 16 years collected hourly climatic data

\section{ANALYSIS OF THE ENERGY SECTOR IN GAZA STRIP}

The Palestinian Authority imports most of the regions' energy from neighbours mainly from Israel (55\%), and Egypt (8\%); the rest (37\%) is generated in the unique Gaza power plant. Palestinian government is trying to make a reconstruction and development scheme of the infrastructure, including the energy sector. They are expected to make advantage of this opportunity and develop a reliable and secure energy strategy based 
on renewable energy. Independent renewable energy projects provide decentralized and reliable electricity generation, which is urgently needed in Palestine.

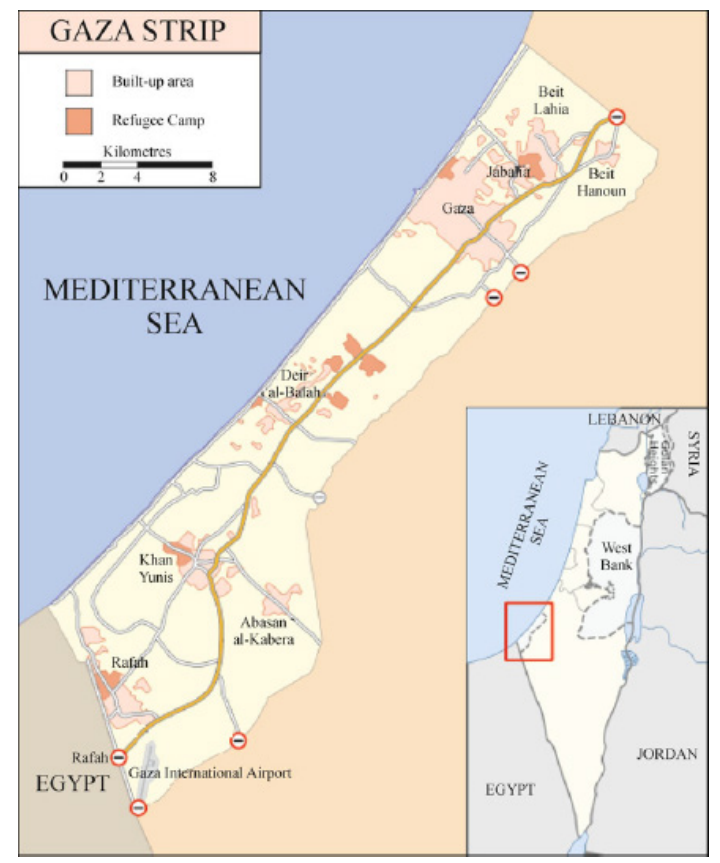

Figure (1). Location and the cities of Gaza Strip

Although governmental levels are not doing very well in the renewable energy sector, there are several encouraging moves in other sectors. The Energy Research Centre (ERC), which was established in 1996 at An-Najah National University (ANNU) has been conducting important research in this field, including: development, system design, feasibility studies and training. The centre has expanded its strategy to include the impacts of energy on global environment, health and social development

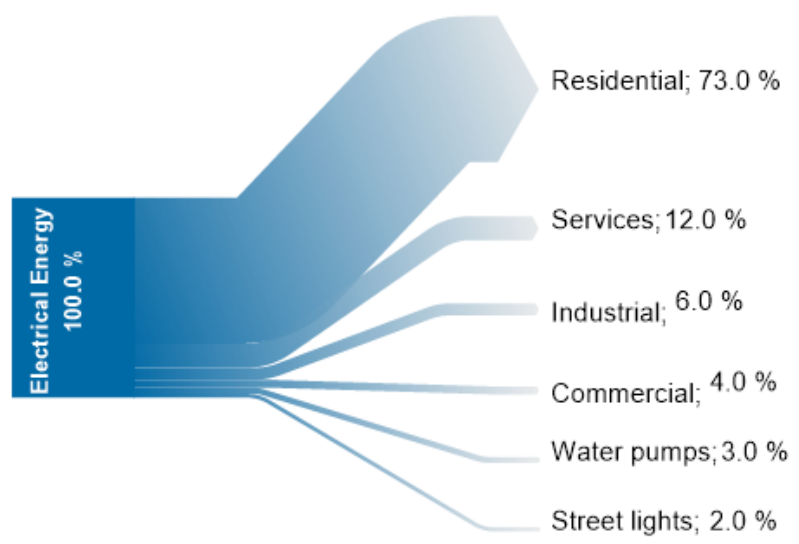

Figure (2). Sankey diagram of electricity consumption by sectors in Gaza Strip [2] 
Table (1). Imported energy in Palestine by type of energy in year 2016 [2]

\begin{tabular}{ccccccccc}
\hline $\begin{array}{c}\text { Electricity } \\
(\mathrm{MWh})\end{array}$ & $\begin{array}{c}\text { Gasoline } \\
\left(\mathrm{m}^{3}\right)\end{array}$ & $\begin{array}{c}\text { Diesel } \\
\left(\mathrm{m}^{3}\right)\end{array}$ & $\begin{array}{c}\text { Fuel } \\
\text { Oil } \\
\left(\mathrm{m}^{3}\right)\end{array}$ & $\begin{array}{c}\text { Kerosene } \\
\left(\mathrm{m}^{3}\right)\end{array}$ & $\begin{array}{c}\text { LPG } \\
(\text { ton })\end{array}$ & $\begin{array}{c}\text { Bitumen } \\
(\text { ton })\end{array}$ & $\begin{array}{c}\text { Oils \& } \\
\text { Lubricants } \\
\text { (ton) }\end{array}$ & $\begin{array}{c}\text { Wood\& } \\
\text { Charcoal } \\
\text { (ton) }\end{array}$ \\
\hline $1,024,120$ & 53,999 & 239,707 & - & 150 & 59,915 & 748 & 25 & 427 \\
\hline
\end{tabular}

\section{WIND DATA COLLECTION}

In this study, wind speed and direction data at $10 \mathrm{~m}$ above the ground is provided by Meteoblue AG Switzerland as hourly time-series for 16 years from 2000 to 2015 for three cities in Gaza Strip. These cities are selected so that covered all the Strip, Jabalia is located in the north, Deir-albalah is located in the centre and Rafah is located in the south. Figure 3 represents the wind-rose and the probability density distribution functions plots of the hourly wind speed for the 16 years for the three selected cities; $80 \mathrm{~m}$ above the ground, by using WRPLOT view 7.0.0 (wind rose plots for meteorological data from Lake Environmental, 2011).

\subsection{Climatic parameters variation with altitude}

Wind speed near to the ground changes with altitude, which requires an equation that predicts the wind speed at one height in terms of the measured speed at another height. For a wind turbine, it is also necessary to know the wind speed at its hub height. The most common expression is the power law, expressed as [9]:

$$
v=v_{0}\left(\frac{\mathrm{Z}}{\mathrm{Z}_{0}}\right)^{\alpha}
$$

where $v$ is wind speed estimated at desired height, $Z ; v_{0}$ is wind speed measured at the reference height, $Z_{0}$. The exponent $\alpha$ is Hellmann exponent or wind shear coefficient, It depends on site, time, season and height of wind speed measurements. Numerically, $\alpha$ lies in the range of $0.05-0.5$, with the most used value of $1 / 7$ (applicable normally to low surface irregularity and well exposed sites). Using this value for $\alpha$, the measured values of wind speed were induced to $80 \mathrm{~m}$, the hub height of the selected wind turbine [10].

The air temperature $\mathrm{T}(\mathrm{Z})$ and air pressure $\mathrm{P}(\mathrm{Z})$ are also varying with the altitude. For this reason, correction must be made through equations (2) and (3) (at low altitudes) for temperature in $(K)$ and pressure in $(\mathrm{kPa})$ respectively [11]:

$$
\begin{aligned}
& \mathrm{T}(Z)=\mathrm{T}\left(Z_{0}\right)-0.0065 \times\left(Z-Z_{0}\right) \\
& \mathrm{P}(\mathrm{Z})=\mathrm{P}\left(\mathrm{Z}_{0}\right)-0.0113 \times\left(Z-Z_{0}\right)
\end{aligned}
$$

Accordingly, and from the gas law, $\rho(Z)$ the density of the air is also varied squirearchy with the varied of the temperature and the pressure according with the relation:

$$
\rho(Z)=\frac{3.48432 \times P(Z)}{T(Z)}
$$

\section{SIMULATION OF WIND POWER AND WIND TURBINE CHARACTERISTICS}

For assessment of wind energy potential for a place, and consequently the possible electricity generation, we need to process meteorological data in several mathematical equations. Wind power density has been chosen over wind speed because the power density integrates in a single number the combined effect of 
wind speeds distribution and the dependence of power on air density, as well as the cube of wind speed. The maximum extractable wind power from a wind mill working at its optimum efficiency is $\mathrm{P}_{\max }$ which is expressed as [6]:

$$
P_{\max }(\mathrm{Z})=0.2963 \rho \mathrm{Av} v^{3}
$$

Where $A$ is the area swept by the rotor in $\left[m^{2}\right], \rho$ is the air density in $\left(\mathrm{kg} / \mathrm{m}^{3}\right)$, and $v$ is the wind speed in $(\mathrm{m} / \mathrm{s})$. The power duration curves are drawn from velocity duration curves using equation (1). The area under the power duration curve represents the energy potential, that is the maximum annual wind energy.

\subsection{Probability density function $f(v)$}

Wind speed for a given location can be characterized by probability distribution functions. Weibull and Rayleigh functions can be used to describe wind speed distribution if direct measurements of wind speed and wind frequency are not available. The Weibull distribution is expressed mathematically by a frequency function $f_{W}(v)$ as [12]:

$$
f_{\mathrm{W}}(v)=\frac{\mathrm{k}}{\mathrm{c}}\left(\frac{v}{\mathrm{c}}\right)^{\mathrm{k}-1} \mathrm{e}^{-\left(\frac{v}{\mathrm{c}}\right)}
$$

where $c$ is the scale parameter, unit of speed; $k$ is the shape parameter; $v$ is wind speed. Once the mean and variance of the wind speed $(\sigma)$ are known, the following approximation can be used to calculate the Weibull parameters $c$ and $k$ :

$$
\begin{aligned}
& k=\left(\frac{\sigma}{v}\right)^{-1.086} \\
& c=\frac{\bar{v}}{\Gamma(1+1 / \mathrm{k})}
\end{aligned}
$$

Where the symbol $\Gamma$ denotes to Gamma function.

For simplification, some particular values of the gamma function were presented in [13] are demonstrated graphically for small positive values of $x$ in Figure 4. A trend line is added to the figure attached with the polynomial that presented the values of $\Gamma(\mathrm{x})$ with high precision. The independent variable $\mathrm{x}$ is presenting the term $(1+1 / k)$ in eq. (3):

$$
\bar{v}=\frac{1}{\mathrm{n}} \sum_{i=1}^{n} v_{i}
$$

And

$$
\sigma^{2}=\frac{1}{n-1} \sum_{i=1}^{n}\left(v_{i}-\bar{v}\right)^{2}
$$

The other distribution function is the Rayleigh distribution $f_{R}(v)$. This distribution is a special case of Weibull distribution and validate situation where the dimensionless shape parameter $k$ of the Weibull distribution is assumed to be equal to 2. Probability density function of the Rayleigh distribution is given by:

$$
f_{R}(v)=\frac{\pi v}{2 v^{2}}\left[-\left(\frac{\pi}{4}\right)\left(\frac{v}{\bar{v}}\right)\right]
$$




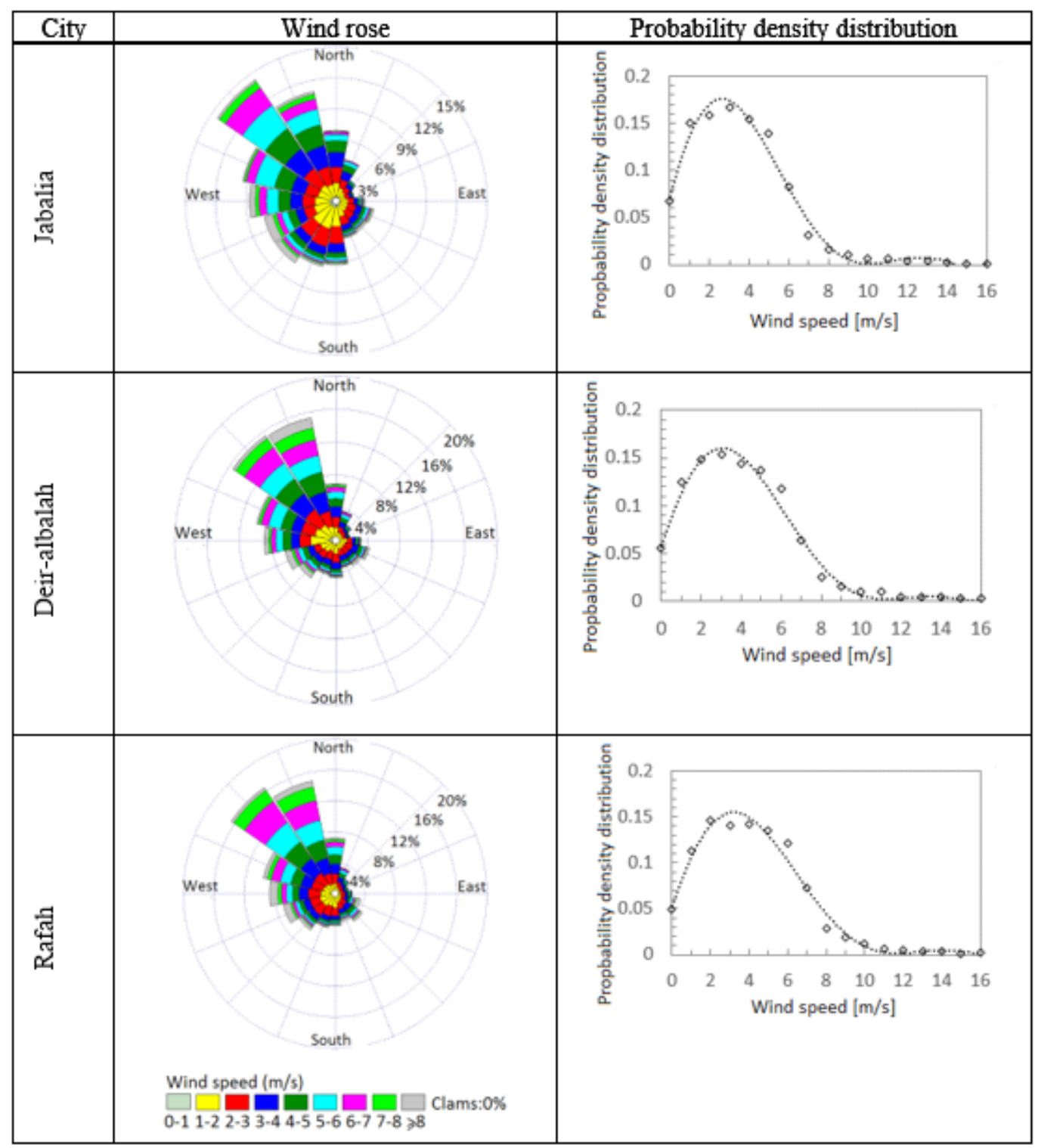

Figure (3). Wind rose and the probability wind density distribution function for the three selected cities.

\subsection{Average power in the wind $\bar{P}_{w}$}

The average power $\bar{P}_{w}$ in the wind can be expressed as:

$$
\overline{\mathrm{P}_{w}}=\frac{1}{2} \rho A \int_{0}^{\infty} v^{3} f(v) d v
$$


Where $f(v)$ is the probability density distribution function. If $f(v)$ is the Weibull density function, the average power becomes [14]:

$$
\overline{\mathrm{P}}_{w}=\frac{\rho \mathrm{A} \bar{v}^{3} \Gamma(1+3 / \mathrm{k})}{2[\Gamma(1+1 / \mathrm{k})]^{3}}
$$

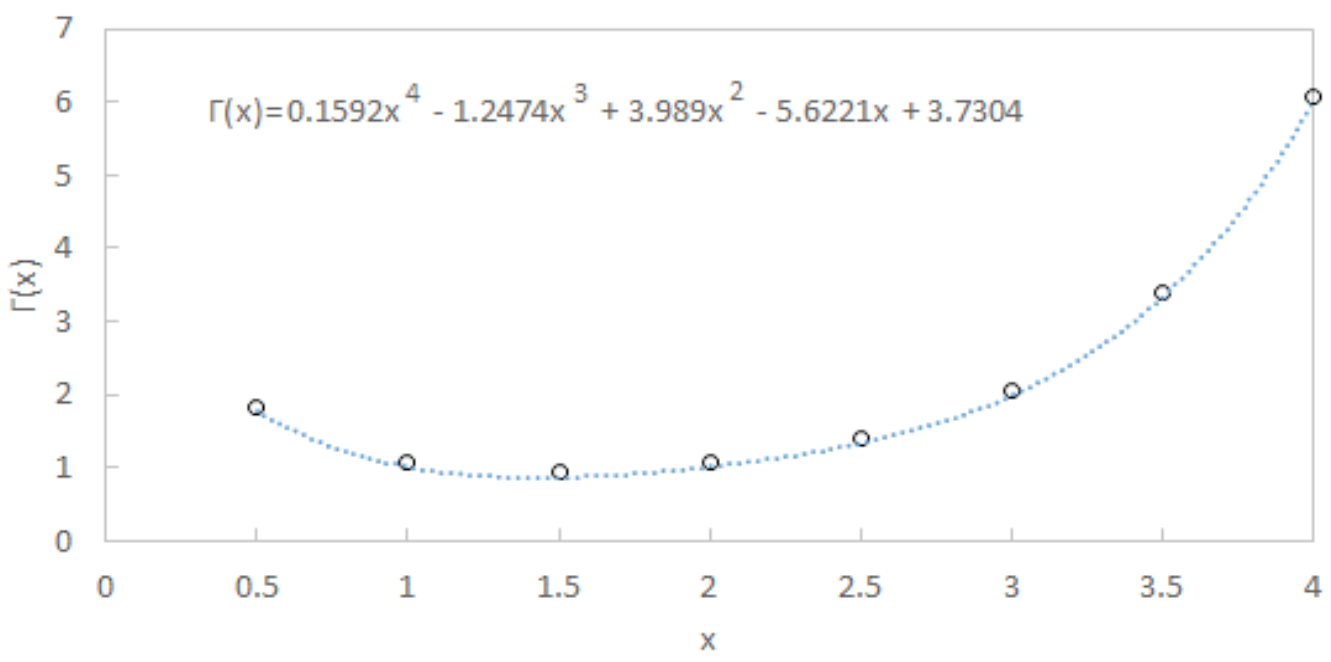

Figure (4). Graphical and polynomial presentation of gamma function [13]

At the last the power generation by a specific wind turbine can be calculated as:

$$
\overline{\mathrm{P}}_{\text {gen }}=\int_{\text {cut }- \text { in }}^{\text {cut }- \text { out }} f(v) P(v) d v
$$

where $P(v)$ is the power curve of the wind turbine, cut-out and cut-in speeds respectively. The annual energy production Wh/year is calculated using the following equation:

$$
\mathrm{E}_{\text {annual }}=8760 \times \mathrm{P}_{\text {gen }}
$$

\subsection{Probability for different wind speed}

For most wind turbines, the range of cut-in wind speed is $3.0-4.0 \mathrm{~m} / \mathrm{s}$, so the probability $f(v \geq 3)$ or $f(v \geq 4)$ must be identified. Figure 5 presents a statistic chart for number of hours per year $T\left(v \geq v_{\text {cut }-i n}\right)$ in which the wind speed is greater than or equal to a specified speed for example the cut in speed for Rafah city at $80 \mathrm{~m}$ above the ground and also the curve fitting.

It is evidence from the figure 5 that in Rafah, the operating hours of turbines can reach 8390 hours per year (96\%) if the cut-in speed is $3.0 \mathrm{~m} / \mathrm{s}$, and 6715 hours (77\%) if the cut-in speed is $4.0 \mathrm{~m} / \mathrm{s}$ (assuming the cutoff wind speed is infinite). Figure 5 is important for economic feasibility. For more convenience to deals with mathematical correlation, equation (12) and (13) obtained by SegmaPlot software, they present the statistical data depicted in figure 5 with high precision. 


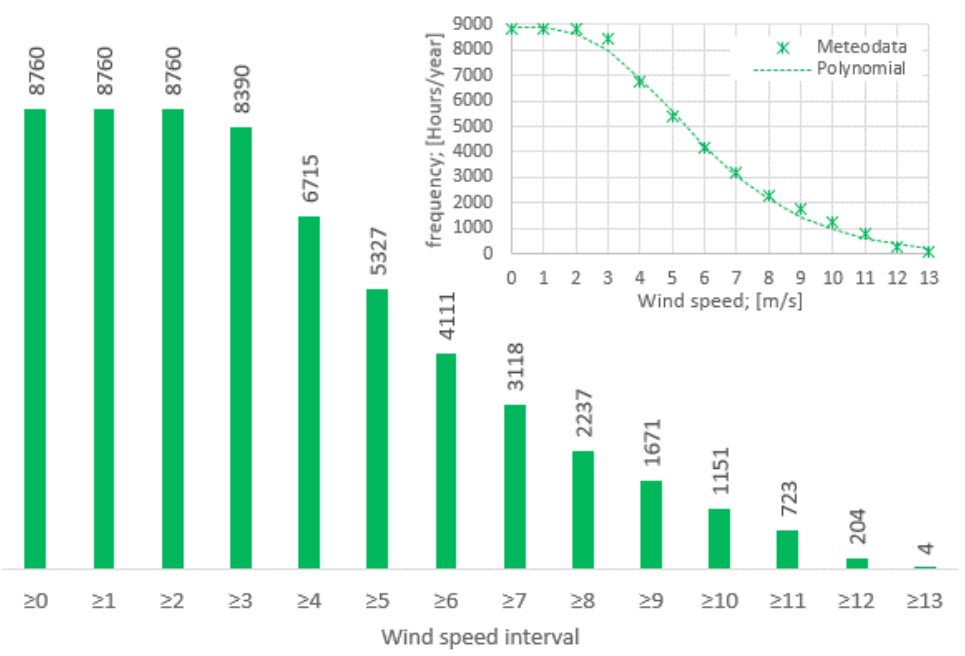

Figure (5). A histogram and curve fitting of number of hours for occurring different wind speed at $80 \mathrm{~m}$ above the ground for Rafah city

$$
\mathrm{T}\left(v \geq v_{\text {cut }- \text { in }}\right)=8925.9-9043.84 e^{\left[-\left(\frac{1018.91-\nu}{1012.24}\right)^{413.873}\right]}
$$

Consequently, the probability of speeds occurrence greater than or equal to a specific speed will be found as:

$$
f\left(v \geq v_{\text {cut }- \text { in }}\right)=\frac{1}{8760} \mathrm{~T}\left(v \geq v_{\text {cut }- \text { in }}\right)
$$

\subsection{Power output of the wind turbine}

As different wind generators have different power output performance curves as it illustrated in Figure 6. The wind turbine should be satisfaction three conditions for maximizing energy output:

1. Minimum cut-in speed;

2. The rated wind speed that matches or near - as possible - the maximum-energy wind speed; and

3. Maximum cut-of speed.

Using polynomial regression to define the power output curve of the chosen Gamesa GT128/4500 wind generator. Technical description and characteristics data of the chosen wind generator is documented in the appendix. From figure 6, one can recognize that, the cut in wind speed is $1.0 \mathrm{~m} / \mathrm{s}$, the rated power wind speed is $12.0 \mathrm{~m} / \mathrm{s}$ and the cut out wind speed is $27 \mathrm{~m} / \mathrm{s}$. It is explicitly evident that, the Gamesa wind turbines are created for class I wind speed with low cut-in speed which is very suitable the situation of Gaza Strip. Five expressions are used in order to describe the wind turbine power characteristics as a function in the wind speed, these are [15]:

$$
\mathrm{P}(v)=\left\{\begin{array}{lc}
0, & v<1.0 \text { or } v>27.0 \\
-0.874 v^{4}+19.661 v^{3}-90.865 v^{2}+207.39 v-98.1, & 1.0 \leq v<9.0 \\
-2.424 v^{3}-65.065 v^{2}+2668 v-13956, & 9.0 \leq v<12.5 \\
4500, & 12.5 \leq v<18.0 \\
-193.58 v+7984.5, & 18.0 \leq v<27
\end{array}\right.
$$




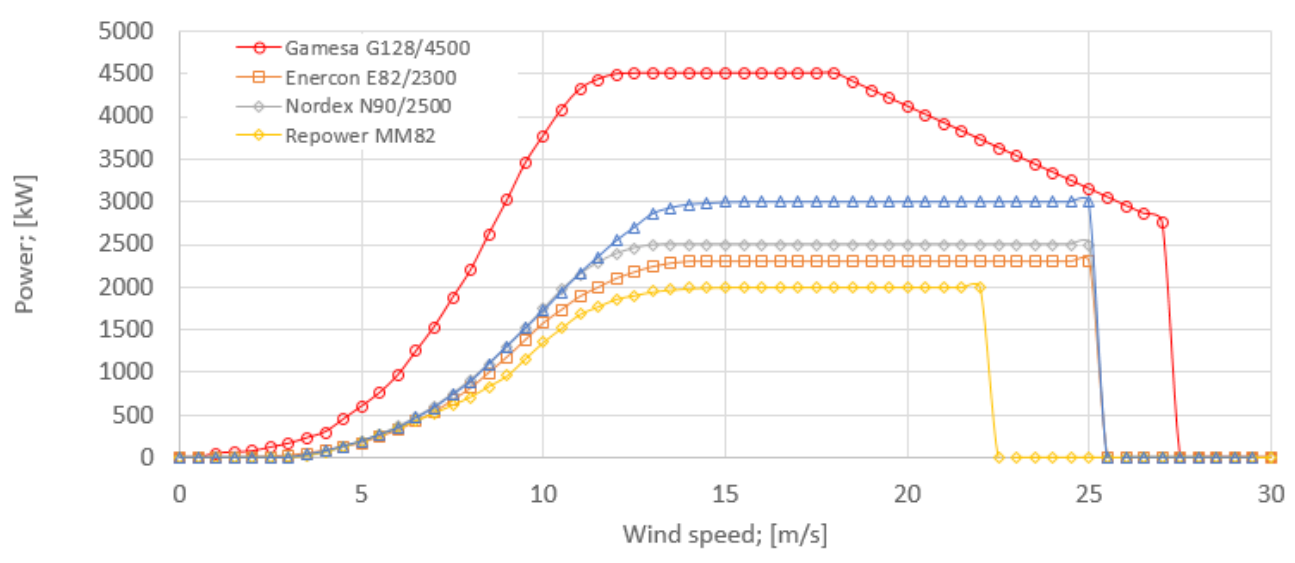

Figure (6). The power curves for selected wind power turbines

Figure 7 illustrates the maximum energy production for Rafah city. The maximum energy production is obtained by introducing the wind speed interval into equation (5) then multiplying by the probability density distribution function $f(v)$. The maximum energy corresponding to the rated wind speed will be expressed as:

$$
E_{\max }\left(U_{\text {rated }}\right)=8.760 P_{\max } f(v)
$$

As it is evidence from Figure 7, the rated wind speed is about $7 \mathrm{~m} / \mathrm{s}$, so we have to choose a wind turbine with rated wind speed of $7 \mathrm{~m} / \mathrm{s}$ for maximum energy output. Indeed, the area under the curve is presented the maximum power extracted from the wind characteristic of the given site.

The utility factor $\left(U_{w t}\right)$ indicates to how much of the wind turbine power capacity is employed, and it is calculated as [15]:

$$
U_{w t}=\frac{\text { real power generated from the turbine }}{\text { power capacity of the turbine }}
$$

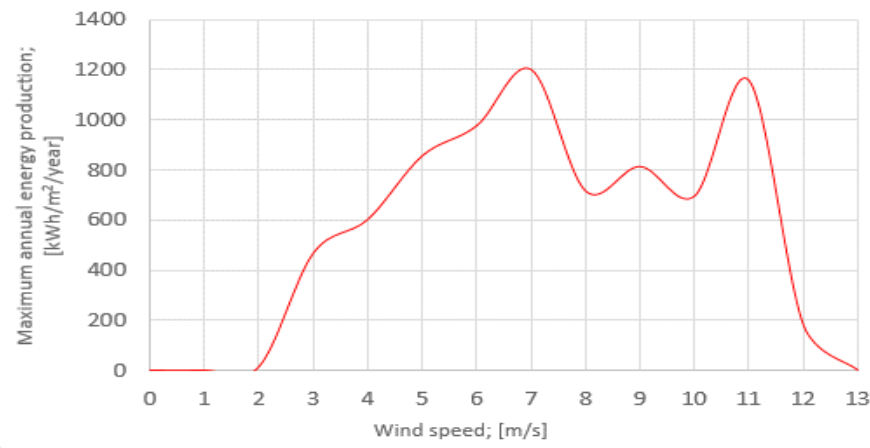

Figure (7). The maximum annual energy production vs the wind speed for Rafah city at $80 \mathrm{~m}$ above ground

\section{RESULTS AND DISCUSSION}

The total annual wind energy production for Rafah, Deir-albalah and Jabalia were evaluated. In the first step the meteorological data is reformatted and tabulated in separate sheets for each city by using MATLAB software. Then the output files are uploaded to WRPLOT view 7.0.0 (wind rose plots for meteorological data 
from Lake Environmental software 2011) in order to plot the wind rose and the frequency distribution of the three cities. While for the statistical and mathematical analysis, the Ms Excel software is used, three separate sheets are created for the considered cities

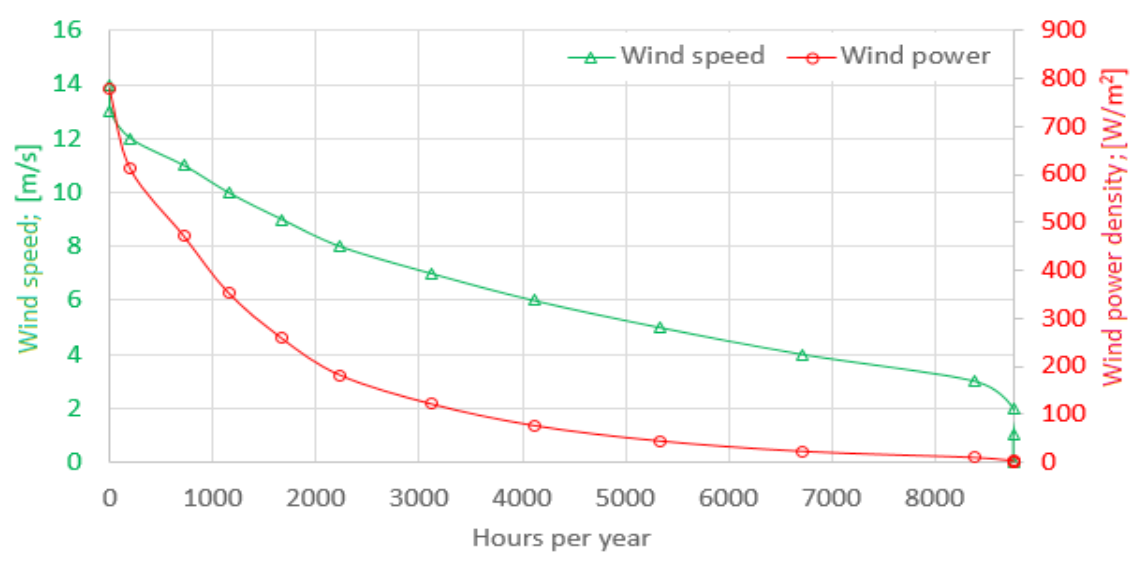

Figure (8). Velocity and power duration curves for Rafah city

The potential of wind energy is calculated using equation (9), and the results tabulated in Table 2. Table 2 also, presents annually and monthly mean velocity over 16 years, the shape parameter $(k)$, the scale parameter $(c)$, and the average wind energy potential for the selected sites in Gaza Strip. While Figure 8 depicts velocity and power duration curves for Rafah city.

Table (2). Average monthly and annually mean wind speed $(\mathrm{m} / \mathrm{s})$, the Weibull parameters and power density $\left(\mathrm{W} / \mathrm{m}^{2}\right)$ for the selected sites at $80 \mathrm{~m}$ above the ground.

\begin{tabular}{lccccccccccccc}
\hline Month & \multicolumn{3}{c}{ Rafah } & \multicolumn{3}{c}{ Deir-albalah } & \multicolumn{3}{c}{ Jabalia } \\
\hline & $\begin{array}{c}\bar{v} \\
(\mathrm{~m} / \mathrm{s})\end{array}$ & $\mathrm{k}$ & $\begin{array}{c}\mathrm{c} \\
(\mathrm{m} / \mathrm{s})\end{array}$ & $\begin{array}{c}\bar{P}_{w} \\
\left(\mathrm{~W} / \mathrm{m}^{2}\right)\end{array}$ & $\begin{array}{c}\bar{v} \\
(\mathrm{~m} / \mathrm{s})\end{array}$ & $\mathrm{k}$ & $\begin{array}{c}\mathrm{c} \\
(\mathrm{m} / \mathrm{s})\end{array}$ & $\begin{array}{c}\bar{P}_{w} \\
\left(\mathrm{~W} / \mathrm{m}^{2}\right)\end{array}$ & $\begin{array}{c}\bar{v} \\
(\mathrm{~m} / \mathrm{s})\end{array}$ & $\begin{array}{c}\mathrm{k} \\
\bar{P}_{w} \\
\left(\mathrm{~W} / \mathrm{m}^{2}\right)\end{array}$ \\
\hline Jan. & 6.79 & 1.70 & 6.33 & 446.0 & 5.27 & 1.63 & 5.96 & 217.7 & 4.93 & 1.54 & 5.53 & 191.8 \\
Feb. & 7.11 & 1.60 & 6.98 & 547.4 & 5.93 & 1.53 & 6.65 & 336.8 & 5.50 & 1.42 & 6.08 & 297.3 \\
Mar. & 6.76 & 2.07 & 5.23 & 365.2 & 4.43 & 2.01 & 5.11 & 105.7 & 4.05 & 1.94 & 4.65 & 83.1 \\
Apr. & 6.48 & 1.93 & 6.08 & 341.1 & 4.99 & 1.95 & 5.74 & 154.2 & 4.70 & 1.85 & 5.38 & 135.3 \\
May & 5.43 & 1.87 & 4.89 & 207.0 & 4.17 & 1.90 & 4.79 & 92.5 & 3.72 & 1.92 & 4.27 & 64.8 \\
Jun. & 6.43 & 2.02 & 4.92 & 321.2 & 4.12 & 2.06 & 4.75 & 83.4 & 3.73 & 2.07 & 4.30 & 61.2 \\
Jul. & 6.33 & 1.67 & 4.26 & 368.4 & 3.69 & 1.72 & 4.21 & 70.7 & 3.20 & 1.68 & 3.63 & 47.2 \\
Aug. & 6.10 & 1.84 & 4.54 & 298.1 & 3.83 & 1.83 & 4.39 & 74.4 & 3.30 & 1.77 & 3.77 & 49.3 \\
Sep. & 6.19 & 1.96 & 4.91 & 293.3 & 4.24 & 2.01 & 4.88 & 92.3 & 3.60 & 1.97 & 4.14 & 57.4 \\
Oct. & 5.77 & 2.22 & 4.87 & 215.2 & 4.09 & 2.13 & 4.71 & 78.8 & 3.53 & 2.15 & 4.07 & 50.4 \\
Nov. & 5.63 & 2.47 & 5.26 & 183.9 & 4.23 & 2.28 & 4.89 & 83.0 & 3.81 & 2.18 & 4.39 & 62.5 \\
Dec. & 6.20 & 1.94 & 4.90 & 298.3 & 4.01 & 1.92 & 4.61 & 81.7 & 3.79 & 2.00 & 4.36 & 66.4 \\
\hline Annual & 6.34 & 1.86 & 5.25 & 331.1 & 4.41 & 1.83 & 5.05 & 113.1 & 3.98 & 1.75 & 4.54 & 86.7 \\
\hline
\end{tabular}

\subsection{Average yearly probability density function}

The Weibull and Rayleigh distribution are calculated for Rafah city as an average for the 16 years. The recorded wind data shows that, $k$ (the shape parameter) is found to be 1.69 , and $\mathrm{c}$ (the scale parameter) is $4.91 \mathrm{~m} / \mathrm{s}$ using Equations (3-6). The distributions are shown in Figure 9. 


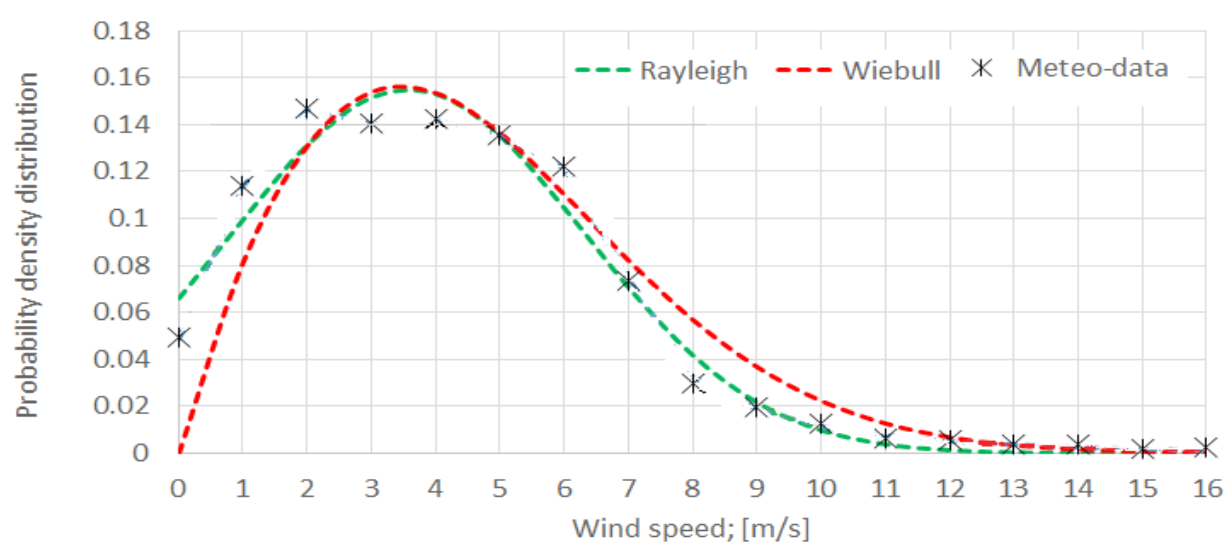

Figure (9). A comparison of the probability wind density distribution function obtained by Weibull and Rayleigh models and the meteo-data for Rafah city at $80 \mathrm{~m}$ above grd for the 16 years.

It is clear from figure 9 that, the Weibull function does not implicitly fit the distribution of wind speed data (because we have zero wind speeds). However, the Rayleigh function is better representing the data.

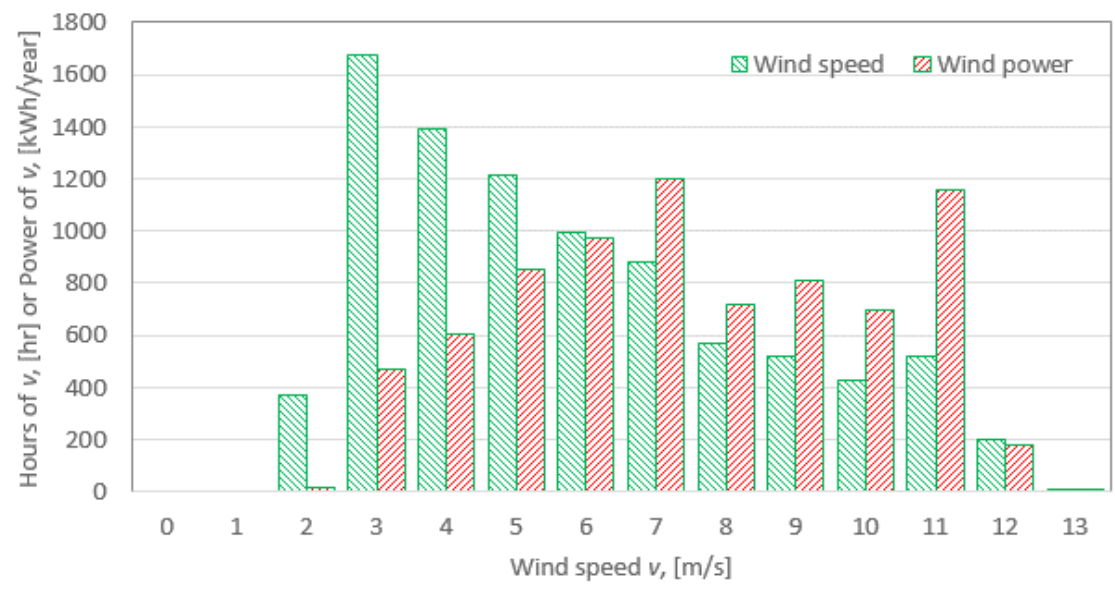

Figure (10). The power at any wind speed with the hours the wind blows at that speed for Rafah city at $80 \mathrm{~m}$ above the ground and for Gamesa G128-4.5 MW turbine

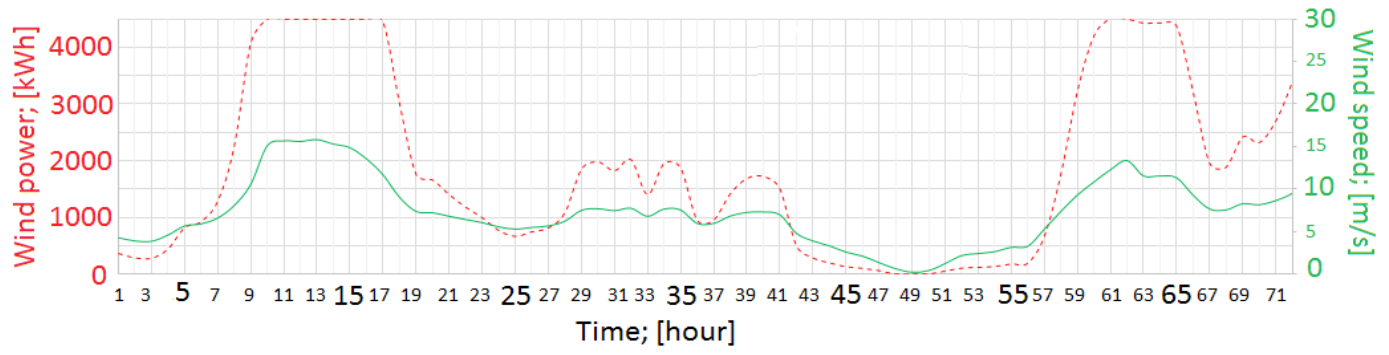

Figure (11). The hourly power production and wind speed variation for the first 72 hours of January average of (2000-2015) for Rafah city at $80 \mathrm{~m}$ above grd with Gamesa G128-4.5 turbine 

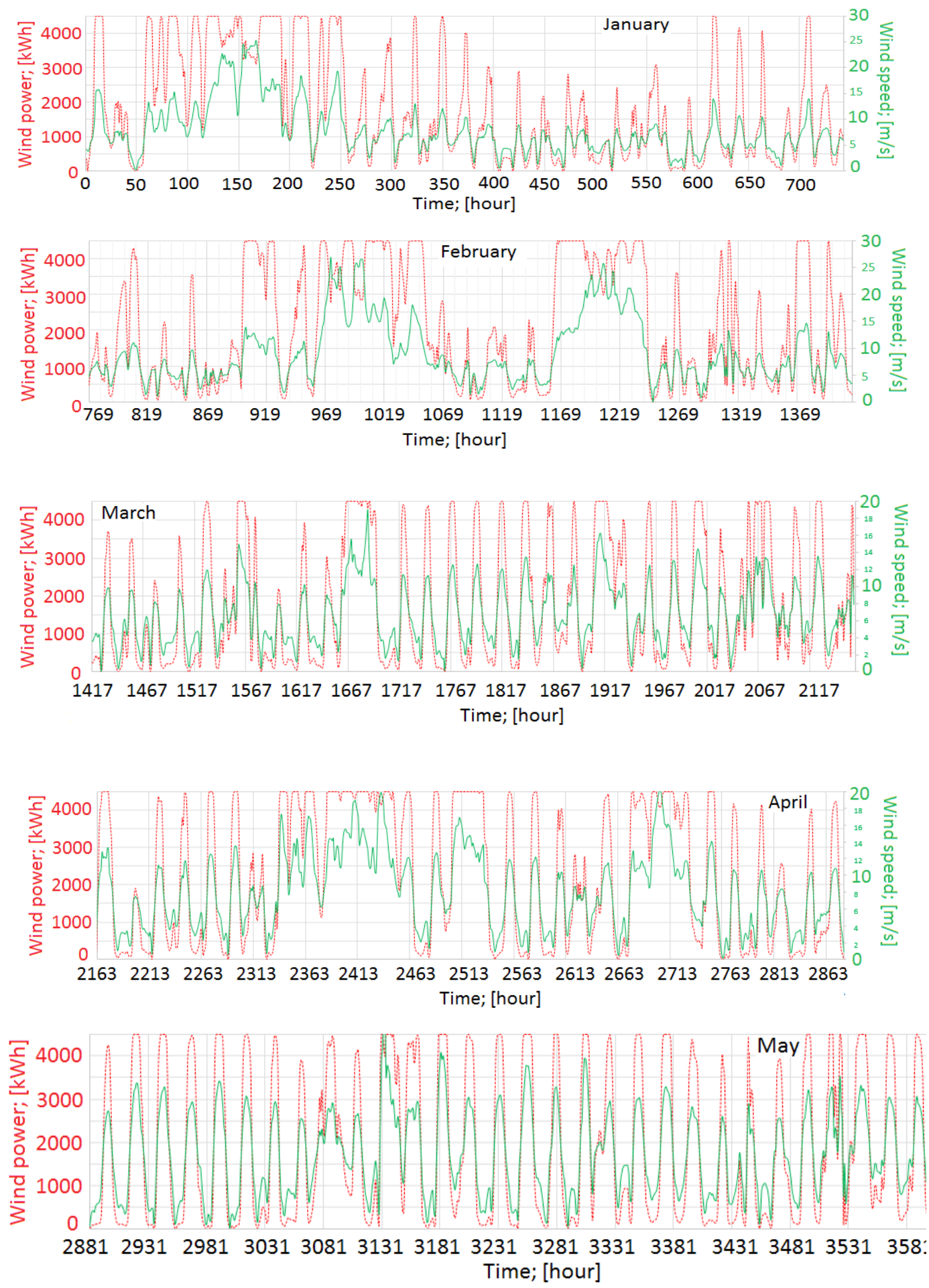

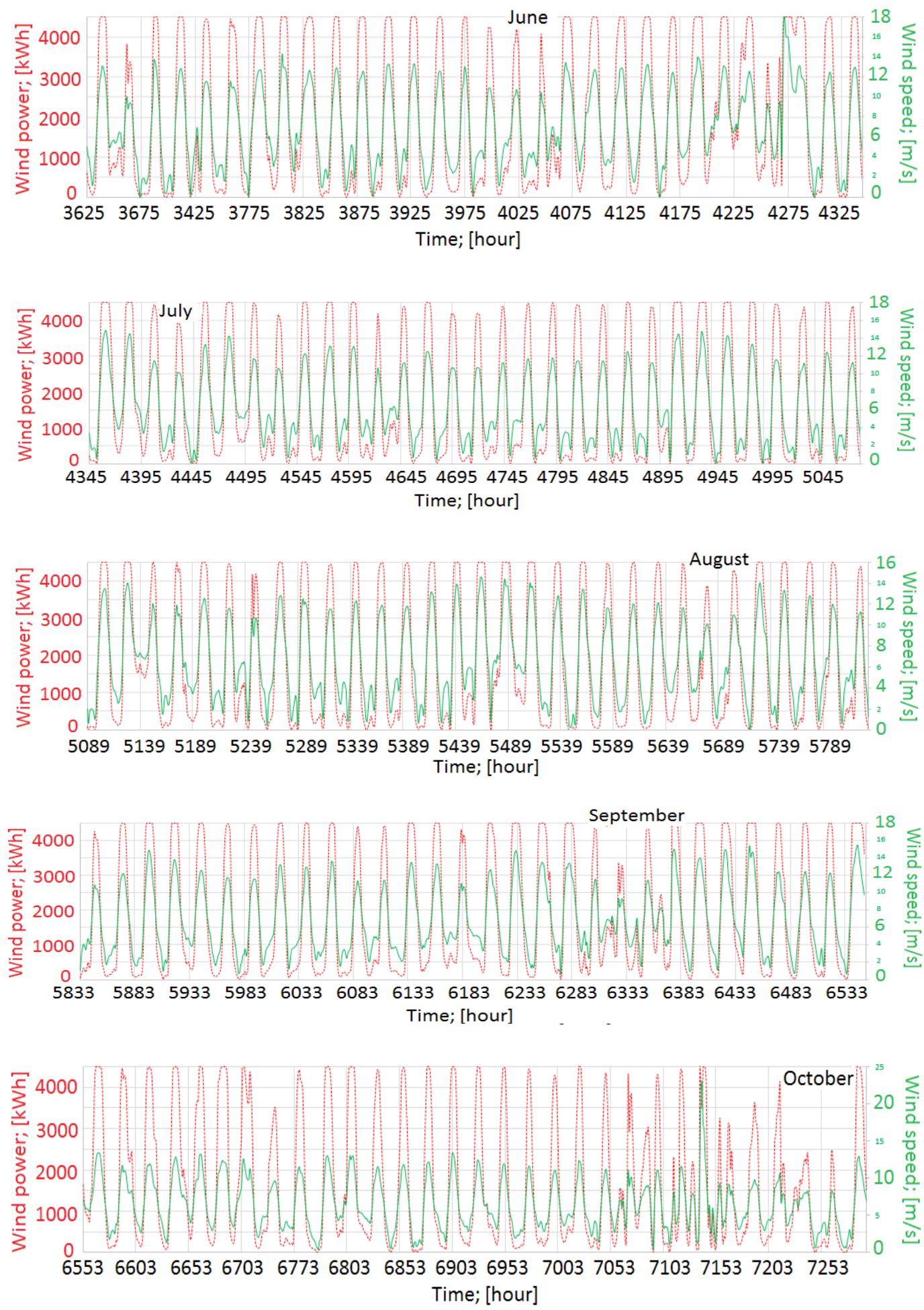

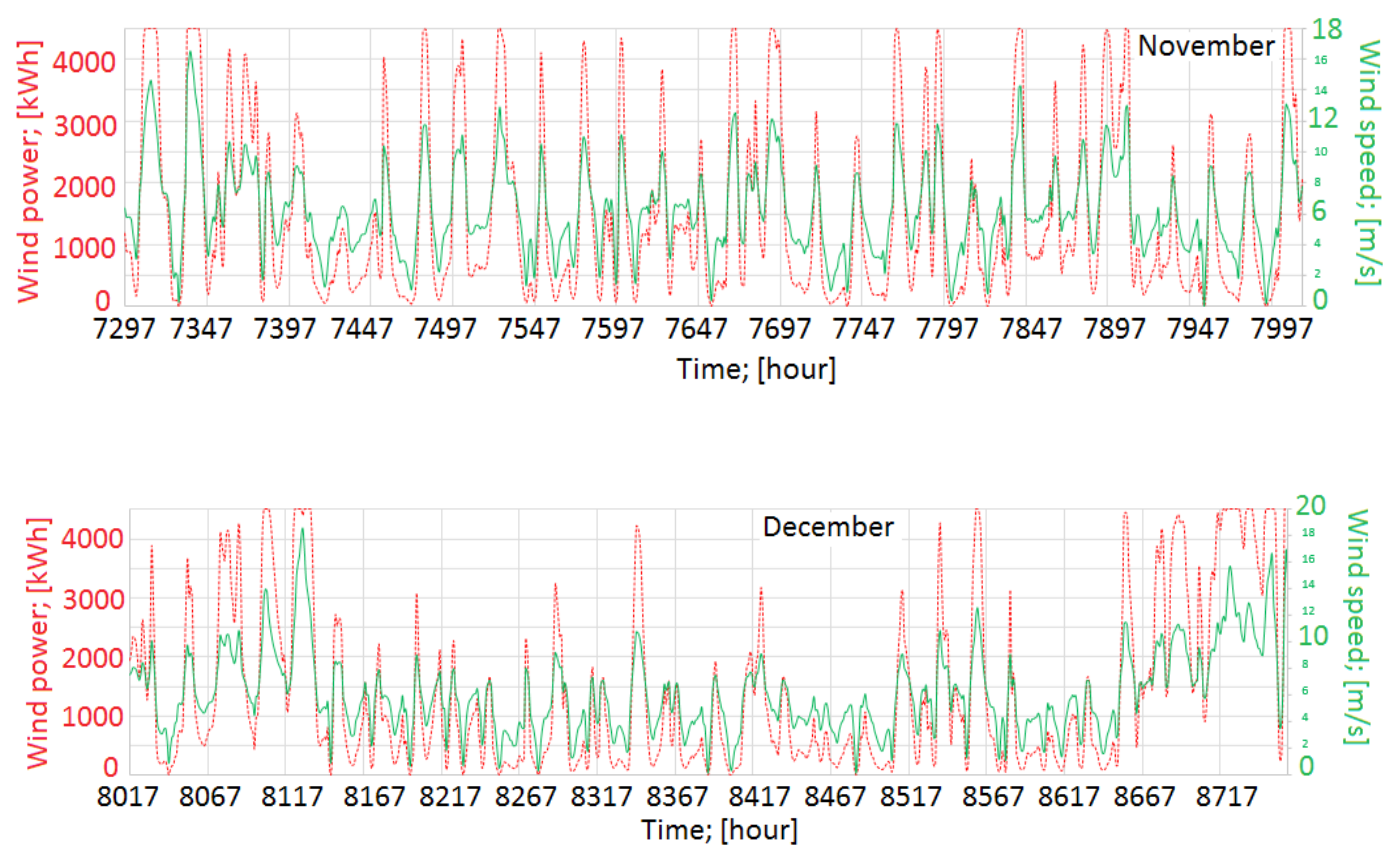

Figure (12). The average hourly power production and average wind speed for each month (2000-2015) for Rafah city at $80 \mathrm{~m}$ above the ground with Gamesa G128-4.5 turbine

\subsection{Estimating the annual energy production}

The total kWh of energy produced for a specific wind turbine is estimated from the combination of the power at any wind speed with the hours the wind blows at that speed as given in equation (14). Weibull or Rayleigh statistical distribution can be alternatively used in the case that only the average wind speed is known. Figure 10 corresponds to Gamesa G128-4.5 MW turbine and hourly wind speed. Figure 11 illustrates the hourly power production and wind speed variation for the first 72 hours of January (2000-2015). While Figure 12 illustrates the hourly power production and the average wind speed through the 16 years for Rafah city at $80 \mathrm{~m}$ above the ground every month.

Accordingly, the total power generated from one Gamesa G128-4.5 wind turbine can be obtained as the area under the curve of power of Figure 12. Table 3 tabulated the monthly power generated and also the total annual power is presented.

As it indicates in Table 3 the utility factor of Gamesa G128-4.5 wind turbine is greater than PV solar systems which equal to in best conditions $30 \%$ (at STC).

Table (3). Annual and monthly power generated and the utility factor for Rafah

\begin{tabular}{|c|c|c|c|c|c|c|c|c|c|c|c|c|c|}
\hline Item & Jan. & Feb. & Mar. & Apr. & May. & Jun. & Jul. & Aug. & Sep. & Oct. & Nov. & Dec. & Ann. \\
\hline MWh & 1385 & 1383 & 1334 & 1649 & 1419 & 1434 & 1281 & 1353 & 1339 & 1246 & 1070 & 1047 & 15962 \\
\hline$U_{w t}$ & 0.414 & 0.457 & 0.398 & 0.509 & 0.424 & 0.443 & 0.383 & 0.404 & 0.413 & 0.372 & 0.330 & 0.313 & 0.404 \\
\hline
\end{tabular}




\section{CONCLUSIONS}

This paper deals with 16 years hourly climatic data for three sites in Gaza Strip in order to determine the best location to build up the first wind power farm in the Palestinian territory. The data used in the research were provided from Meteoblue for the purpose of assessment the wind energy potential in three sites, which present the all Gaza-Strip (Jabalia in the north, Deir-albalah in the centre and Rafah in the south of the Strip). This data is published for the first time. Wind speed and the frequency measurements were taken from Gaza Strip showed that Rafah City has the highest wind energy potential, with an annual average wind speed of $6.38 \mathrm{~m} / \mathrm{s}$ and a speed higher than $7 \mathrm{~m} / \mathrm{s}$ for 3118 hours per year (36\%) and about 200 hours of rated wind speed. Since Rafah sites are less populated and have isolated and scattered areas, this increases the economic feasibility of utilizing wind energy.

More energy can be produced by using higher towers and larger rotor diameters. A tower of $140 \mathrm{~m}$ height is technically available from Gamesa G128-4.5 MW turbine for example at $140 \mathrm{~m}$ above the ground the energy produced by one turbine increases by $10.315 \%$ of that produced at $80 \mathrm{~m}$ altitude.

\section{ACKNOWLEDGMENTS}

Authors would like to thank Mr. Amer Oudeh from Meteoblue AG [www.meteoblue.com] for the support by providing us with meteorological observations for Gaza Strip. Our thanks also going to Mr. Said Nassar the Mayor of Deir-albalah municipality and to Mr. Sameer Mutair the Co-chairman of the Palestinian Energy Authority and the Chairman of electricity distribution company in the Gaza Strip. Thanks also to the Palestinian Central Bureau of Statics.

\section{APPENDIX}

Wind turbine model Gamesa G128-4.5 MW characteristics [16]

\begin{tabular}{ll}
\hline Parameter & Value \\
\hline Cut-in wind speed & $1.0 \mathrm{~m} / \mathrm{s}$ \\
Rated wind speed & $12.0 \mathrm{~m} / \mathrm{s}$ \\
Cut-out wind speed & $27.0 \mathrm{~m} / \mathrm{s}$ \\
Rotor diameter & $128.0 \mathrm{~m}$ \\
Swept area & $12,868.0 \mathrm{~m}^{2}$ \\
Number of blades & 3 \\
Power density 1 & $349.7 \mathrm{~W} / \mathrm{m}^{2}$ \\
Power density 2 & $2.9 \mathrm{~kW} / \mathrm{m}^{2}$ \\
Hub height & $81 / 120 / 140 \mathrm{~m}$ \\
Type & Steel tube/concrete \\
Shape & Conical \\
\hline
\end{tabular}

\section{REFERENCES}

[1]. British Petroleum (PB) website available at the URL: https://www.bp.com/en/global/corporate/energy-economics/ statistical-review-of-world-energy/renewable-energy/wind-energy.html,

[2]. The Palestinian Central Bureau of Statics, 2017, Ramallah - Palestine.

[3]. Mustafa El-Hawi, Case Study: "Renewable Energy in the Gaza Strip: Short, Mid, and Long Term concepts", prepared by 
PalThink for Strategic Studies and Friedrich-Ebert-Stiftung, October 2014, Gaza, Palestine.

[4]. A.DeMeij, J.F.Vinuesa, V.Maupas, J.Waddle, I.Price, B.Yaseen, A.Ismail, Wind energy resource mapping of Palestine, Renewable and Sustainable Energy Review 56 (2016), 551-562.

[5]. De Meij A, Vinuesa J-F, Maupas V, Waddle J, Price I, Yaseen B, Wind energy resource mapping of Palestine. Renew Sustain Energy Rev 2016; 56:551-62. http://dx.doi.org/10.1016/j.rser.2015.11.090.

[6]. Ahmed F. Hassoon, Assessment potential wind energy in the north area of Iraq, International Journal of Energy and Environment (IJEE), Volume 4, Issue 5, 2013, pp.807-814, https://www.academia.edu/9056711

[7]. Yaseen B. Renewable energy applications in Palestine. Palestinian energy and environment research center (pec)-energy authority, technical department, Palestine. In: Proceedings of the 2nd international conference for the Palestinian environment, Palestine; 2009.

[8]. Anwar Abu-Zarifa, Design of a Stand-Alone Power Wind Turbine Optimized for Low Wind Speed in Gaza, International Journal of Energy Engineering 2014, 4(5): 89-93.

[9]. I. Youm , J. Sarr , M. Sall , A. Ndiaye and M.M. Kane, Analysis of wind data and wind energy potential along the northern coast of Senegal, Rev. Energ. Ren. Vol. 8 (2005) 95 - 108. https://www.cder.dz/download/Art8-2_3.pdf

[10]. Considering a standard aerogenerator for Englewood Cliffs, NJ. Lin Lu, Hongxing Yang, John Burnett, Investigation on wind power potential on Hong Kong islands-an analysis of wind power and wind turbine characteristics, Renewable Energy 27 (2002) 1-12.

[11]. Geometric altitude vs. temperature, pressure, density, and the speed of sound derived from the 1962 U.S. Standard Atmosphere.

[12]. https://www.digitaldutch.com/atmoscalc/tableatmosphere.htm

[13]. A. Juaidi, F. Montoya, I. Ibrik, F. Agugliaro, An overview of renewable energy potential in Palestine, Renewable and Sustainable Energy Reviews 65 (2016) 943-960.

[14]. https://en.m.wikipedia.org/wiki/Gamma_function

[15]. Murat Gokceka, Ahmet Bayulken, Sukru Bekdemir, Investigation of wind characteristics and wind energy potential in Kirklareli, Turkey, Renewable Energy 32 (2007) 1739-1752.

[16]. A.K. Raja, Amit P. Srivastava and Manish Dwivedi, Power plant engineering, 2006 New Age International (P) Ltd., Publishers, New Delhi, p. 110.

[17]. https://www.thewindpower.net/turbine_en_81_gamesa_g128-4500.php 